\title{
SUBCONJUNCTIVAL BUPIVACAINE IN STRABISMUS SURGERY
}

\author{
H. T. EL-KASABY, N. E. HABIB and A. M. MARCZAK \\ Wolverhampton
}

\begin{abstract}
SUMMARY
A prospective study was performed to assess the effect of subconjunctival bupivacaine on pain relief following strabismus surgery. A total of 36 children were randomly allocated to receive either subconjunctival infiltration of bupivacaine or normal saline at the conclusion of surgery. Post-operative pain was evaluated using a 4-point assessment score. Subconjunctival bupivacaine provided significantly better post-operative pain relief $(P<0.001)$. We suggest that it could be used routinely in strabismus surgery, as it improves post-operative comfort thereby facilitating day case surgery.
\end{abstract}

Day case surgery has become an accepted practice for many ophthalmological procedures, including strabismus surgery. Patients undergoing strabismus surgery are mainly pre-school children who are particularly vulnerable to being separated from their familiar surroundings. ${ }^{1}$ Day case surgery minimises the length of time young children are in hospital, which in turn reduces the cost of the procedure. We were thus prompted to investigate the optimum perioperative analgesia for facilitating early discharge.

Local anaesthesia by wound infiltration at the end of surgery provides effective analgesia after a multitude of surgical procedures. The technique is used extensively after cholecystectomy, ${ }^{2}$ excision of benign breast lump, ${ }^{3}$ herniorrhaphy in adults ${ }^{4}$ and inguinal herniotomy in children. ${ }^{5}$ Bupivacaine is frequently used in regional anaesthesia, as in peri- or retro-bulbar anaesthesia in ophthalmic surgery, and has a duration of action of $4-6$ hours. The aim of this study was to assess the effect of subconjunctival bupivacaine on post-operative pain relief after strabismus surgery in children.

\section{PATIENTS AND METHODS}

Following Ethics Committee approval, a total of 36 children were enrolled in the study. There were 19 girls and 17 boys with a mean age of 5 years (range 2-9 years).

From: Wolverhampton and Midland Counties Eye Infirmary, UK.

Correspondence to: Mr. H. T. El-Kasaby, Birmingham and Midland Eye Hospital, Church Street, Birmingham B3 2NS, UK.
Informed consent was obtained from the parents of all the children. All patients underwent elective surgery on two horizontal muscles for correction of strabismus. Patients presenting for repeat surgery were excluded.

Patients were randomly divided into two equal groups, one of which received subconjunctival bupivacaine at the end of surgery and the other subconjunctival saline. Randomisation instructions were placed in sealed envelopes at the beginning of the trial, which were then mixed and numbered and placed in the operating theatre.

All patients were in group 1 according to the American Society of Anesthesiologists classification of physical status, ${ }^{6}$ indicating good general health. Both groups received lignocaine cream (EMLA, Astra) to the proposed venepuncture site. Induction was either intravenous or inhalational according to the anaesthetist's preference. Anaesthesia was maintained by the patient spontaneously breathing a mixture of oxygen, nitrous oxide and halothane. During the procedure the patients were monitored using electrocardiography, pulse oximetry and non-invasive blood pressure monitoring. Short-acting intravenous analgesics, which are effective for less than 30 minutes, were used if indicated. Post-operative analgesia was prescribed on an 'as required' basis and consisted of paracetamol suspension orally (age 2-5 years, $120-250 \mathrm{mg}$; 6-10 years, $250-500 \mathrm{mg}$ ) or intramuscular pethidine $1 \mathrm{mg} / \mathrm{kg}$.

Surgery was performed by four experienced surgeons (consultant/senior registrar). The surgical technique was uniform in all operations, including an identical conjunctival approach and suture material. At the conclusion of surgery either a subconjunctival injection of $0.25 \mathrm{ml}$ bupivacaine hydrochloride BP $0.5 \%$ or a similar volume of normal saline $(\mathrm{NaCl} \mathrm{BP} 0.9 \%)$ was given over each operated muscle. No topical medications were applied in the immediate post-operative period and none of the eyes was padded.

Post-operative pain assessment was made on a 4-point scale: 1 , sleeping; 2 , awake and quiet; 3 , agitated; 4 , crying. All patients were assessed for pain by the same senior ward nurse and the parents independently at 30 minutes 
and at 1,2 , and 4 hours after surgery. The nurse and the parents were blind to the randomisation. The administration of any analgesics was recorded.

Statistical analysis of the assessment scores was undertaken using the Mann-Whitney $U$-test. A nonparametric test was selected for analysis because of the relatively small sample size.

\section{RESULTS}

There was no significant difference in age and sex distribution between the two groups. Each patient was given four pain scores, one for each of the time intervals, which were then summed to produce a total score. The higher the total score, the more uncomfortable the patient would have been. The median of the total scores for the bupivacaine group, as assessed by the nurse, was 6 (range 4-9) and for the saline group 9.5 (range 5-12) (Fig. 1). The median difference was 3.00 (95\% confidence interval 2.00 to 4.00 ) and $P<0.001$. The total scores as assessed by the parents were not statistically significantly different to the nurse's assessment. The median difference for the parents' total scores was 2.00 (95\% confidence interval 1.00 to 3.00 ) and $P<0.001$.
The nurse's pain assessment scores are shown in Fig. 2. The bupivacaine group consistently achieved better analgesia, but this was only statistically significant at $30 \mathrm{~min}$ utes $(P<0.001)$ and 1 hour $(P=0.001)$.

The total dose of bupivacaine used was $2.5 \mathrm{mg}$, which is well below the toxic dose. No systemic or local side effects were encountered in any of the patients.

In the bupivacaine group only 3 patients $(17 \%)$ received oral paracetamol suspension compared with 5 patients (28\%) in the saline group. This was not statistically significant. No patients in either group required pethidine.

\section{DISCUSSION}

This study shows that bupivacaine $0.5 \%$ injected subconjunctivally at the conclusion of strabismus surgery significantly reduces post-operative pain. Our results are comparable to those of other workers who used wound infiltration with bupivacaine to provide post-operative analgesia in general and paediatric surgery. ${ }^{2-5}$

Pain following strabismus surgery is thought to be predominantly conjunctival. Nevertheless, deeper structures such as Tenon's capsule and sclera may contribute to post-

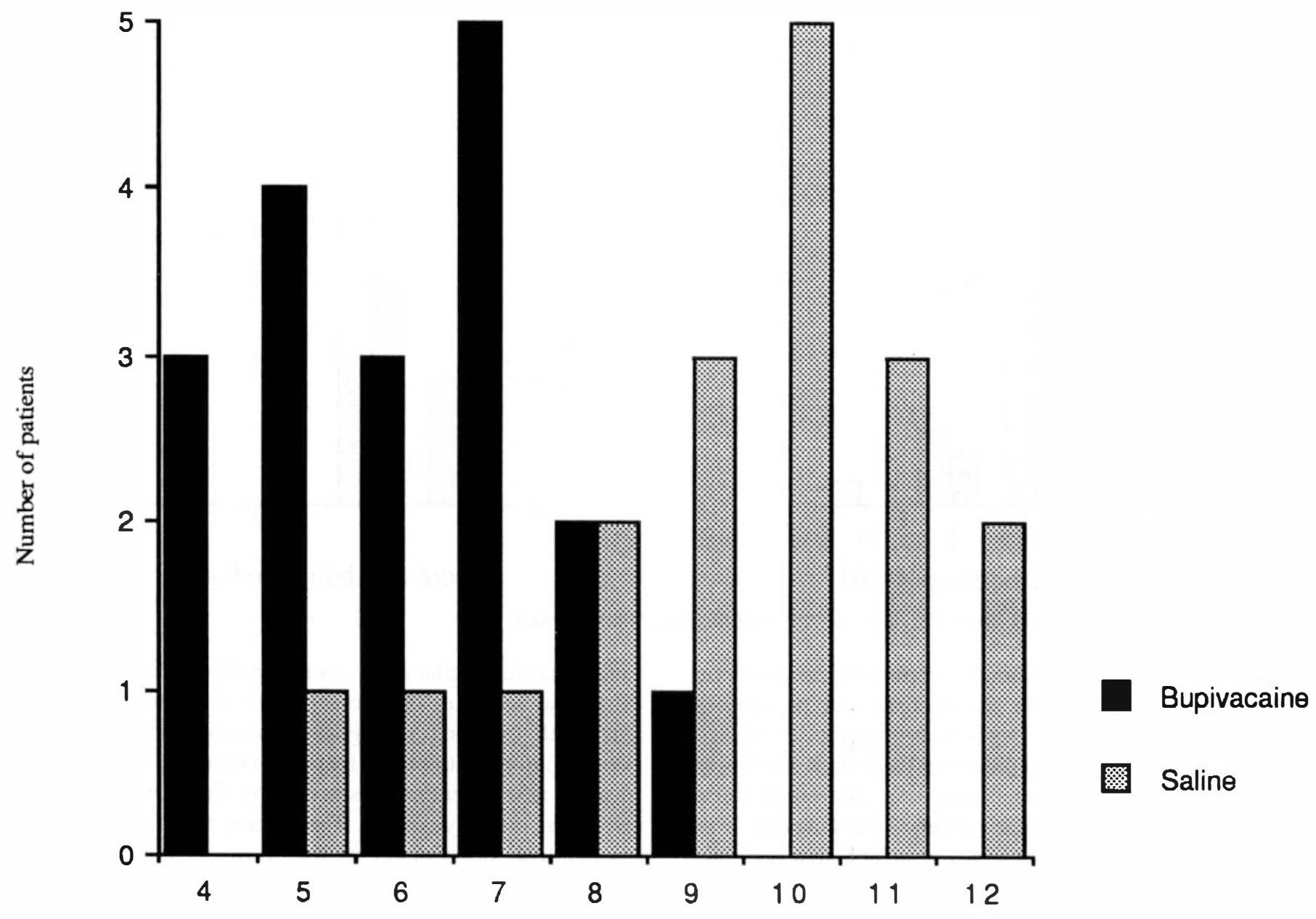

\section{Total score}

Fig. 1. Total post-operative assessment scores by the nurse. 


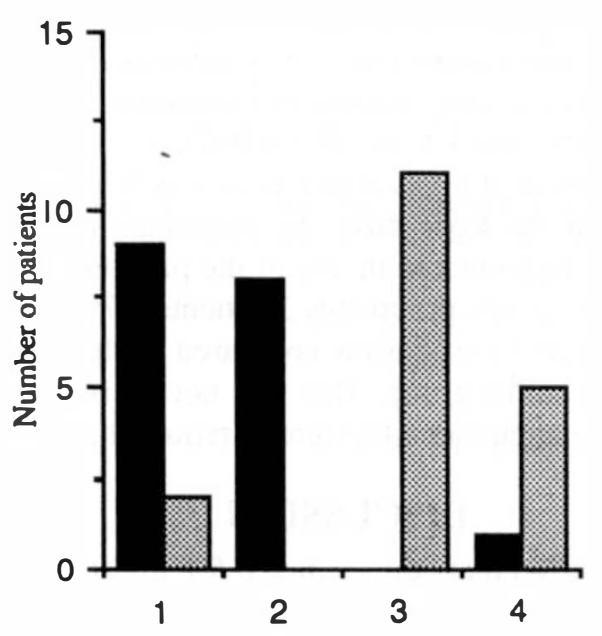

Score at 30 minutes, $\mathrm{p}<0.001$

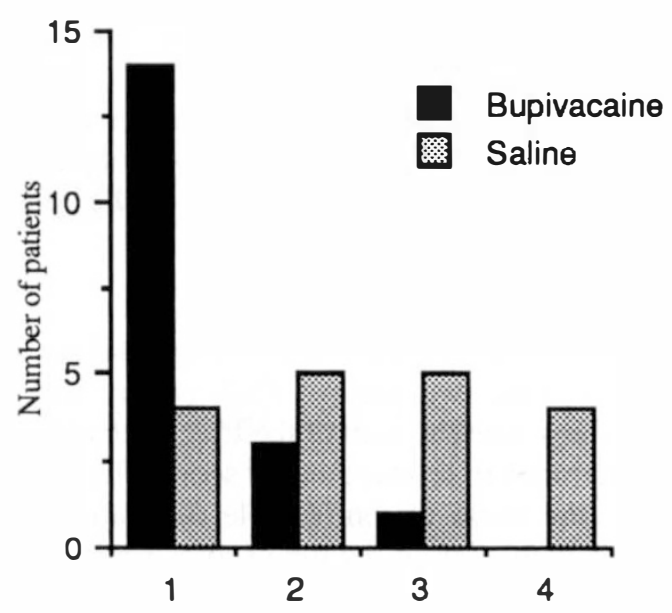

Score at 1 hour, $p=0.001$

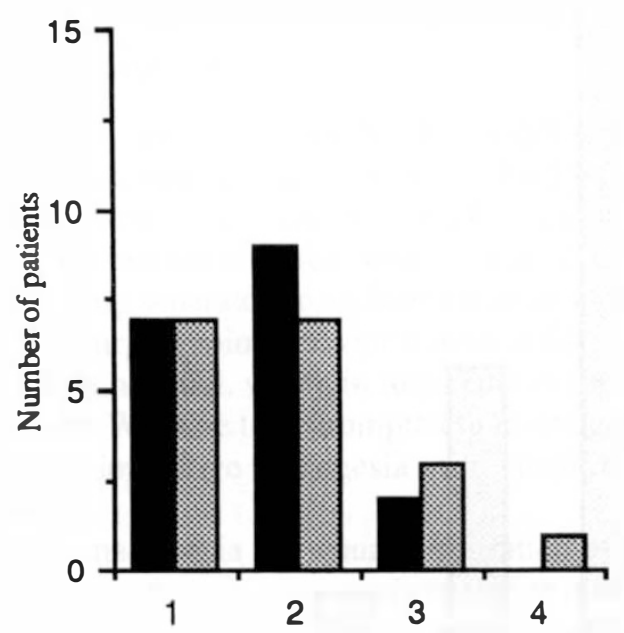

Score at 2 hours, $\mathrm{p}=0.561$

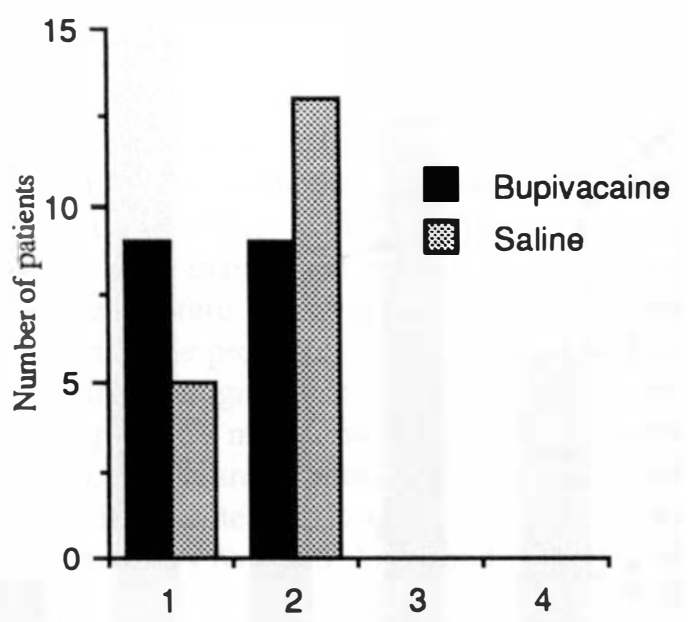

Score at 4 hours, $p=0.427$

Fig. 2. Post-operative assessment scores by the nurse at the four time intervals.

operative discomfort. Although rectus muscles have no pain receptors, stretching ${ }^{7}$ as in resection procedures would produce pain. A long-acting anaesthetic injected subconjunctivally seemed the logical approach to provide adequate analgesia for those structures that could cause pain following strabismus surgery. Bupivacaine was chosen as it is a long-acting local anaesthetic that is widely used in ophthalmic surgery, and it provided adequate analgesia with no side effects or toxicity in the doses used.

Premedications and long-acting opiates were not allowed in this trial, thus avoiding sedation, nausea and vomiting and in turn aiding earlier discharge. Pain assessment was also made easier.

Pain can be particularly difficult to assess in children.
With careful explanation, older children can complete analogue scales or choose a picture which reflects how they feel. ${ }^{8}$ In younger age groups, assessment by an observer or parent is the only feasible method. ${ }^{9}$ We used the 4-point assessment score since many children in the trial were less than 4 years old. The parents participated in the assessment independent of the ward nurse to give the results more validity.

It is particularly important in day case paediatric surgery to ensure that post-operative discomfort is relieved in order to minimise, for both patients and parents, the stress and upset that arise from pain and the adverse effects of analgesic drugs. Subconjunctival bupivacaine is easily administered at the conclusion of strabismus surgery and 
provides good post-operative analgesia. We suggest that it could be used routinely, especially in day case surgery.

The authors wish to thank Mr. P. I. Murray for critically reading the manuscript, and Ms. H. S. Jones for her help with statistical analysis of the data.

Key words: Analgesia, Bupivacaine, Post-operative pain, Strabismus, Surgery.

\section{REFERENCES}

1. Hadaway EG, Ingram RM, Traynar MJ. Day case surgery for strabismus in children. Trans Ophthalmol Soc UK 1977;97: 23-5.

2. Patel JM, Lanzafame RJ, Williams JS, Mullen BV, Hinshaw JR. The effect of incisional infiltration of bupivacaine hydrochloride upon pulmonary functions, atelectasis and narcotic need following elective cholecystectomy. Surg Gynecol Obstet 1983;157:338-40.
3. Owen H, Galloway DJ, Mitchell KG. Analgesia by wound infiltration after surgical excision of benign breast lumps. Ann R Coll Surg Engl 1985;67:114-5.

4. Hashemi K, Middleton MD. Subcutaneous bupivacaine for postoperative analgesia after herniorrhaphy. Ann R Coll Surg Engl 1983;65:38-9.

5. Fell D, Derrington MC, Tylor E, Wandless JG. Paediatric postoperative analgesia: a comparison between caudal block and wound infiltration of local anaesthesia. Anaesthesia 1988;43:107-10.

6. American Society of Anesthesiologists. New classification of physical status. Anesthesiology 1963;24:111.

7. Burton H. Somatosensory sensation from the eye. In: Moses RA, editor. Adler's physiology of the eye: clinical applications, 7th ed. St. Louis: Mosby, 1981:74.

8. White JB, Stow P. Rationale and experience with visual analogue toys. Anaesthesia 1985;40:601-3.

9. Wandless J. The control of postoperative pain in children. Frontiers of Pain 1991;3:1. 